\title{
Environmental Implications of Metal Binding by the Novel Chalkophore Methanobactin
}

\author{
Jeremy D. SEMrau ${ }^{*}$, BaOHUA GU ${ }^{2}$, Alan A. \\ DiSPIRITO $^{3}$, CHRISTINA KANG-YUN ${ }^{1}$, XUJUN LIANG ${ }^{2}$, \\ XIA LU ${ }^{2}$, AND PHILIP DERSHWITZ ${ }^{3}$ \\ ${ }^{1}$ The University of Michigan, Ann Arbor MI 48109 USA \\ (correspondance: jsemrau@umich.edu) \\ ${ }^{2}$ Oak Ridge National Laboratory, Oak Ridge TN 37831 USA \\ ${ }^{3}$ Iowa State University, Ames IA 50011 USA
}

Some methanotrophs, or methane-oxidizing bacteria, produce a novel chalkophore for copper collection ("chalko" is Greek for copper) called methanobactin. To date, two general forms of MB have been characterized (Figure 1). Copper is bound by $\mathrm{MB}$ via an $\mathrm{N}_{2} \mathrm{~S}_{2}$ ligand set associated with two heterocyclic rings.

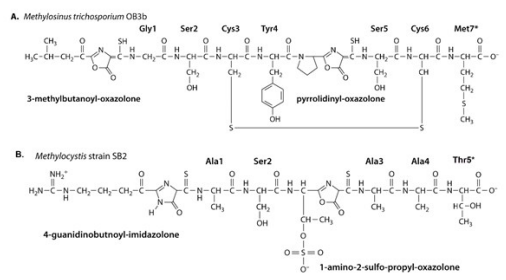

Fig. 1. Examples of (A) Group I and (B) II MBs [1]

With this ligand set, other metals, e.g., mercury, are also strongly bound. MB also enables methanotrophs to bind and degrade methylmercury $(\mathrm{MeHg})$, despite these bacteria not having the canonical organomercurial lyase (MerB). Although MB is required for methanotrophic-mediated $\mathrm{MeHg}$ degradation, it is not sufficient. Rather, MB serves a delivery device that enables methanotrophs to take up $\mathrm{MeHg}$ where it is degraded by some other mechanism. Here we discuss the affinity and transformation of copper and mercury by MB and subseqent uptake of metal-MB complexes by methanotrophs. Further, we provide evidence on the mechanism responsible for $\mathrm{MeHg}$ degradation in methanotrophs. From the data collected, MB-mediated mercury detoxification is a hitherto unidentified but important mechanism contolling mercury availability and toxicity in situ. Thus MB has many potential applications beyond copper acquisition.

[1] Semrau et al. (2018). Appl Environ Microbiol E02289-17 